\title{
Sprinkles and Spacing
}

\section{Mothers' Reactions to Nutrition Programmes in Guatemala's Dry Corridor}

\section{Bronwen Gillespie}

\begin{abstract}
Aвstract: This article explores women's reactions to public health nutrition work in Guatemala, looking specifically at multi-micronutrients, or sprinkles. This anthropological research was carried out in two rural communities in Chiquimula, one of which was in the Maya Ch'orti' region, during the 2017 seasonal period of scarcity. Taking as a starting point the limitations of a medicalised approach to malnutrition, this article discusses how multi-micronutrients are illsuited as a solution for child malnutrition in situations of precarity. Though they are designed to be physiologically effective in reducing nutrition deficiencies in the body, they appear less useful once socio-economic conditions are considered. Women's experience with malnutrition emergencies will be explored to show how health decision-making must be understood in relation to their social context as well as to their expectations for the future.
\end{abstract}

KeYwords: Guatemala, health decision-making, malnutrition, poverty, sprinkles, women

'They gave them to me for my son; they said they are vitamins', said Lidia, ${ }^{1}$ turning to me from where she was stoking the fire, pointing to her boy outside on the patio hiding behind his older sister. Lidia is talking about sprinkles multi-micronutrient powder, a central element of Guatemala's strategy to reduce chronic child malnutrition, which is estimated at $46.5 \%$ of children under five years of age at the national level (Comisión 2016) and over $70 \%$ in one of the districts where my research took place (ACF 2017).

This article discusses how multi-micronutrients are ill-suited as a solution for child malnutrition in situations of precarity. Though they are designed to be physiologically effective in reducing nutrition deficiencies in the body, they appear less useful once socio-economic conditions are considered. Here, I argue that a lack of interest in the product is due to poverty: supplementation does not make sense when families do not have enough food to eat. My research also suggests that mothers make health-related deci- sions not only in regard to what is practical or possible, but also with regard to what is worthwhile: 'worth' must be evident beyond a medical definition and include how health advice fits within people's fears and desires, and their visions for their families.

The article takes as a starting point the limitations of a medicalised approach to malnutrition. Using biomedicine to comprehend or treat life processes previously assumed to be social is often referred to as 'medicalisation' (Conrad 1992; Foucault 1973). Critical scholarship on the medicalisation of hunger and on food scarcity (Harper 2014; Lock and Nguyen 2010; Scheper-Hughes 1992) can be used to raise questions regarding the relevance of Guatemala's nutrition programmes. From a policy point of view, the research here can be considered in light of the call for 'nutrition-sensitive' approaches in development aid and government programming which suggest that investing in areas such as agriculture, women's empowerment, and income-generation are crucial to improving nutrition, in contrast to narrower nutrition- 
specific programmes, which focus on immediate determinants such as adequate food and nutrient intake and disease burden (Ruel et al. 2013). The role of women's empowerment in relation to child health outcomes has been extensively debated in the development studies literature (Presser and Sen 2000). Work on women's agency in health decision-making (Kabeer 1999) will be used to look at nutrition programming not only in terms of what is materially possible, but also how it responds to women's desires and motivations.

This anthropological research was carried out in two rural communities in Chiquimula, one of which was in the Maya Ch'orti' region, during the 2017 seasonal period of scarcity in conjunction with an Action Against Hunger (ACF) child and maternal health and nutrition project. ${ }^{2}$ The opinions and experiences of 130 people were gathered through in-depth conversations held while participating in household chores, such as washing clothes or making tortillas, to capture women's own accounts within the context of their daily lives and social relations within the community. Informants primarily consisted of mothers with children under five years of age, but they also included fathers, community authorities, teens and children, teachers, and healthcare workers. We largely relied on participant observation and semistructured interviews, but we also made use of focus groups and more formal interviews with certain actors.

\section{Malnutrition in Guatemala's Dry Corridor}

This research took place within a region that is known as Guatemala's Dry Corridor due to re-occurring droughts. Climate change leading to unpredictable precipitation has been noted to be threatening livelihoods in the area (MFEWS et al. 2009). The area is subject to regular seasonal periods of scarcity from May or June until August or September. Over 70\% of families in Chiquimula are considered poor (SESAN 2017), and this research was carried out in rural mountainous zones where poverty is concentrated, most of which pertains to the indigenous Ch'orti' region. Very few of the families in the research sites have their own land: most survive on subsistence farming of corn and beans on rented land, which can cover three or four months of family's basic food needs, and on day labour, which is sporadic and seasonal (MFEWS et al. 2009). Coffee-harvesting is the most widespread income-generating activity; however, farmers report that opportunities have re- cently decreased due to the presence of disease in plantations in the zone. Agricultural labour typically brings in Q30 a day ${ }^{3}(\$ 4)$, or double that in more gruelling jobs, while those who are unable or unwilling to travel far beyond the village collect and sell wood for less than $\$ 3$ a day. A United Nations Children's Fund (UNICEF) report cites minimum wage as $\$ 10$ a day and calculates a basic daily food basket as costing almost $\$ 15$ (UNICEF 2015).

These communities are accessible by road but not many vehicles enter. Both do have primary schools and access to a health centre (although one has only been in operation for a few months and is almost an hour's walk uphill). Health services include the regular height and weight monitoring of children under five years of age and a vaccination schedule. Families often visit nurses, and some medicines are available, though both health staff and families complain of shortages in supplies. More complicated cases are sent to the village of Jocotán or the hospital in Chiquimula. Housing ranges from strong adobe constructions with covered patios, to huts of dried bamboo sticks, where the cooking area is barely sheltered from rainstorms and mud. Only a handful of the over 60 homes visited have latrines. Similarly, access to water is limited (in the worst cases, it is a two-hour walk), and while many women do boil water, they dedicate a whole day, every few days, to gathering firewood so that they can do so.

Guatemala's high rates of malnutrition are linked to poverty and inequality in the country (ASIES 2014). Relative access to food is a national issue, as a reduction in purchasing power over the last decade means that families cannot take advantage of the abundant food available in the country; the problem is most severe in rural and indigenous areas (ASIES 2017). Lack of investment in water and sanitation systems is also a crucial factor that has led to high rates of chronic malnutrition (ASIES 2017). Land concentration is increasing: at last measurement, over $92 \%$ of the landholdings (most are infra-subsistence and subsistence-size plots) made use of only $21.9 \%$ of the arable land (ASIES 2017: 182). In the districts where this research took place, precarity is high because many subsistence farmers rent land to be paid with a part of the harvest and then become indebted when drought occurs. Farmers explain that they have lost their own land by failing to repay loans for inputs after low-yield harvests (ASIES 2017). Chronic malnutrition rates are reported as higher amongst indigenous children (58\%), children of women without education $(67 \%)$ and children of the women in the lowest wealth quintile (65.9\%) (Comisión 2016). 
Social indicators for Guatemala, in areas such as education, health and mortality are amongst the worst in the region, surpassed only by Haiti (ACF 2016). Despite having one of the highest GDPs in the Americas, Guatemala spends only about $2.6 \%$ of that on healthcare, the lowest percentage in Latin America (ACF 2016).

At the national level, the nutrition challenge is one of chronic malnutrition, or stunting (low height for age), rather than acute, or wasting (low weight for height) (Chary et al. 2013; Martorell 2012), which affects less than $1 \%$ of the population (MSPAS et al. 2017). The highest rates of stunting affect children aged 18-23 months, and the least affected are those under six months of age (MSPAS et al. 2017), as stunting is generally traced to the shift from breastfeeding to complementary foods (Chary et al. 2013). Nationally, almost $60 \%$ of infants under three months of age are exclusively breastfed, and in indigenous families this rate reaches just under 75\% (MSPAS et al. 2017).

From the early 2000s onwards, the government and international aid partners have focused on 'the first 1,000 days of life' policies to coordinate efforts to reduce stunting in early childhood (Chary et al. 2013). As part of the government's strategy, the health system initiated widespread use of sprinkles in 2012, which were approved for all children from six months to five years of age (MSPAS 2013). Sprinkles contain iron, zinc, folic acid and vitamins (MSPAS 2013) and should be taken daily for two months, mixed with chopped or pureed food, and then be initiated again after a four-month pause. However, the distribution of sprinkles has suffered from a lack of continuity, and health centre staff in the area have reported that stocks had run out at the national level. Although the government has endorsed this as part of its strategy to fight malnutrition, low investment and weak government operativity has led to limited coverage, irregular supply and inconsistent monitoring (ACF 2016). In fact, none of the families connected with this research had received the supplements within the last few months, and even when we sought out mothers who had experience with sprinkles, most had only ever received one dose for a two-month period.

It is important to understand that in the villages where this research took place families understand the term 'malnutrition' in relation to acute rather than chronic malnutrition (the latter being a national priority). Rates of acute malnutrition in the research area are higher than average, and are measured by $\mathrm{ACF}$ to be at around 3\% for children under five years of age (ACF 2017). Acute malnutrition can be a life- threatening condition, and the drive to monitor and rescue children can be observed in the institutional focus in Chiquimula. If children at risk do not show improvement at home, health staff in the community must refer them to public nutrition recuperation services in district centres. Private nutrition recuperation centres also operate in the region, sometimes sending out teams to detect and monitor children at risk and interning emergency cases. Critical research suggests that droughts and subsequent crop failure in the early 2000s led to unprecedented media outcry and a political flurry surrounding cases of severe acute malnutrition in children in the region (Mariano Juarez 2014; Martorell 2012). Stunting, although a widespread national challenge, is less visible both on the body and in terms of the attention it receives in Chiquimula.

\section{Sprinkles and Food Scarcity}

Lidia, introduced above, lives with her husband and five children in a tiny two-room home in a community nestled on a hillside high above Jocotán. As we shucked the first few beans of the harvest from a small parcel of rented land, her toddler snacked on buds of wild plant greens gathered nearby. Lidia received sprinkles from the health centre once last year, and has not seen the product since, but was not eager to receive them again in any case. 'Sprinkles cause malnutrition', she told me. 'I gave them to my boy, mixed with egg, and the egg was wasted. I didn't have another egg; what could I give him to eat?' Several mothers stopped adding sprinkles to food once they noted any rejection on the part of their child. Women report that babies consume sprinkles fairly easily, but that it becomes tricky for those over two years of age to eat:

I mixed it in her food, and when she was just over a year, she ate it all. But later, when she was older, she noticed it, even if I didn't let her see it. She said, 'You put that stuff in my food!', and she didn't want to eat.

In another community, this one with views of the bustling city of Chiquimula spread far below, I went to visit Julia in her tiny hut with a spotless patio out front. I asked her about sprinkles. Her words contrasted with her warm smiley face. 'Oh yes', she exclaimed, 'I use them, but only if I have food. Otherwise, what can I mix them with?' Unlike Lidia, who received some financial aid from an international organisation, Julia said she was not on the list. 'Last 
year, we received WFP. ${ }^{4}$ This year, no. This year, we have to endure. We ate last year, thanks to them'. During these difficult months, they (Julia and her family) mainly eat tortillas (which, due to their consistency, are unsuitable for mixing with sprinkles). She points to her daughters, aged nine and six, who are playing with their sister, a giggling three-yearold: 'If there isn't much food, I tell the big ones: "You can resist, let the little one eat"'.

Many women make fewer meals or ration out their tortillas. I was introduced to Reina, a young mother with a baby in her arms, at a community meeting, and afterwards I walked down the hill with her to her house. I asked whether I could give her a hand, as it was lunchtime. 'No, I am not cooking, because I don't have corn', she replied. 'I will cook when my husband comes back'. Having left to find work for several days, she hoped he would return later that day. Reina and her neighbour cover periods of scarcity collecting wild greens. Her neighbour explained:

All week since my husband left, we have been eating quilate [wild greens]; I cook them in a bit of water and add some salt. Sometimes, I make tortillas because my children ask for them. We don't have money to buy beans. Last time we ate beans [was] when my husband was here.

I met Lidia, Julia and their neighbours in August, when the first harvest was only just starting in some communities; this was in the season when job opportunities are few and far between. Climatic conditions during the last few years have led to crop failure and increasing precarity. One elderly woman, who raised her own seven boys nearby and now lives surrounded by her grandchildren, commented: 'This season of scarcity has always existed. People would look thin, and then they would recover. What has made it worse is the drought'. International organisations do not have enough funding to cover all families in need, and limited government aid arrived late last year, months after the crisis had passed.

Women rely on family networks to survive, borrowing a handful of beans or sending a child to eat with grandparents, but fitting sprinkles into a child's diet is not a priority in these vulnerable conditions. Women do not reject the product itself: in fact, several women insisted that they had finished their twomonth supply, mixing them with bananas when in season, that are often grown beside their houses. However, many other women had given up trying. As one mother explained, 'I didn't finish them. My husband also said, "Why are you giving them to him, if then he doesn't eat his food?"' When food is scarce, it is not likely that mothers decide to persevere with sprinkles; rather, they choose food over supplements.

\section{Illness and Malnutrition}

Mothers report that they discontinued sprinkle use in the case of illness. In one mother's words, 'If the child has diarrhoea or a fever, how would we give it to them?' The community health outreach volunteer, herself a local mother, described the ever-present threat in the early years of life: 'Here, illness follows children; they always have something until they are about five years old'. She told me, quietly, 'People I trust tell me that most mothers are throwing the sprinkles away ... there is no result when children consume them. You can't see the difference'.

Many women labelled sprinkles as vitamins, and several had heard they were good for the brain or for their children's studies. But sprinkles, unlike vaccinations, medicines or even worm pills, were not categorised as relevant in responding to their concerns. Vaccinations are increasingly valued in the community, as women understand they prevent severe illness. When I met Maria just outside the church storage room, which was serving as a makeshift clinic where the nurse was visiting for the morning, she was very anxious, as her daughter's scheduled injection was refused because she had a fever that day. I joined the group of women waiting, holding their babies, and Sofia explained to me, 'I don't come by obligation. Women come here of their own accord, because they want the vaccinations'.

As well as for vaccinations, women make use of the health services for cases of cough, fever and diarrhoea, though they complain that few medications are available. Many mothers also had sought help against severe intestinal worm infestations, and several confessed that they had started to administer worm pills on their own (as health regulations require children to be two years old). ' $\mathrm{My}$ son had a worm coming out of his nose, so I brought him to the health centre, but they said he was too small for the medication. They didn't want to give him pills, so I got money and I bought one for him. About ten worms came out, dead'. Her neighbour Glenda, an outspoken mother of six healthy-looking children, told me that, years before, her own boy had failed to gain weight and was threatened with internment, and that she had realised, in hindsight, that 'it was the worms. ... Now I get the pills and slice off a bit for the baby too'.

Women are aware of the connection between constant illness and malnutrition: they note that sickly 
children are very much at risk: 'They say it's for lack of food that malnutrition gets hold of the body ... but I say it's illness. Illness gives it to them'. Another mother told me that with the continual bouts of vomiting and diarrhoea her daughter lost what she did eat and could not gain weight. A doctor at the recuperation centre in town echoed this point. 'Most of all, it's due to illnesses', he said, referring to the cases of acute malnutrition that are treated at the centre. Health centre staff and policy experts (ASIES 2017) link illness with severe limitations in access to water and sanitation.

\section{Malnutrition as Emergency}

Women fear the cycle of illness, lack of appetite, subsequent malnutrition, and the threat of emergency that forces one to go beyond the village. Glenda, who I mentioned above, described her efforts to ward off acute malnutrition:

My son was fine until he was six months old. Then he got ill. He vomited, had diarrhoea, on and off, until he was about three. A doctor came from Zacapa and said that he was going to take him away, take him from me. He gave me 15 days to see if I could get him to recuperate. It was a shock for me, I had to act. I got him out of malnutrition, giving him food, even though he did vomit. I got him to eat, to recuperate.

As one mother explains, 'One is not happy when her child is malnourished; rather, one is sad because of all the time spent in the hospital. If the child has malnutrition, there is risk of death, and you have to go to the health centre to rescue the child'. Illness that cannot be resolved locally is a threat to the family economy: 'Luckily, I have never had to go to the hospital; there, they don't give one food', said Julia. Margarita, an elderly woman, is still frustrated about her experience with her youngest daughter:

We don't know why she got that illness. They said it was malnutrition. They came to look for malnourished children, and they brought them to Chiquimula. ... We were there 12 days, and I felt so worried because I had left small children at home. The worst was the medicine we bought with money from my husband's pocket, but that was what saved her.

Women interviewed were concerned about having to intern their child, about cost, and about leaving the rest of the family alone at home, but their descriptions also point to a concern about their own roles vis-à-vis that of the health services. Several were angry about losing control over health decision-making. Silvia, for one, did not accept that her son was labelled as malnourished, insisting that he could be treated at home:

They told me that my son was malnourished, but he wasn't. It was just that I got pregnant with my daughter and my milk dried up, so he got thin, but he wasn't malnourished. I got him to recover with incaparina $^{6}$ and eggs.

For villagers, malnutrition is associated with internment or hospitalisation; acute malnutrition is urgent and requires intervention and travel, and it implies costs and stress for the family. Ethnographic research in the area has described families' fears and the conflicts surrounding internment in nutrition recuperation centres for children deemed unlikely to survive at home, linking the increased incursion into homes to rescue severely malnourished children to the 2001 food security crisis in the area and the resulting national media outcry (Mariano Juarez 2014). Women described how the worry of having children taken away spurred them into action, and they reacted with resentment to the notion that better care will be given to their children at the hospital. ${ }^{7}$ Only a few families complained about the local health centre staff. However, complaints of verbal abuse and discriminatory treatment at public health centres have been documented in other regions of the country (Albizu 2015; Berry 2008; Chary et al. 2013). Estela, for one, was still angry about her conflict with a local nurse. As soon as I arrived to visit, she explained her case, indignant, while her daughter-in-law listened quietly in the other doorway, pushing a tiny baby in a hammock. Estela had resolutely refused her newborn granddaughter's hospitalisation (due to low weight), fearing the baby's death in the hospital and hating insinuations that the family would let the baby die at home. (In this instance, the mother could not breastfeed, so Estela, her mother-in-law, who had also recently given birth, fed both infants):

I only go to the health post for weight and height, and vaccinations, because I need their vaccinations, but not to see a nurse. I don't like that they say, 'Your child is going to die; it's your fault'. We don't have babies to put them in boxes!' [understood to be referring to coffins]

The community nurse often resorts to pressuring families, fearing that if the babies die she will be held accountable. She told me about a case: 'Yesterday, a baby arrived almost cold, and I sent them to the hospital, and I yelled, 'Only you, not the Ministry of Health, not the nurse, not the doctor, are responsible for your babies!' Moral discourse circulates around 
the management of illness and malnutrition, and the death of children in the community. Sonia, proud of how she increased her son's weight, commented: 'It is an embarrassment to have a malnourished child. If one commits a crime, for example, if one's child dies in one's arms, one may have to even go to jail'.

Families are caught between healthcare workers' pressure to seek higher-level care outside the village and concerns that the care will imply unaffordable associated expenses and that underfunded public institutions are incapable of resolving illness in any case. As an elderly man explained,

When my son was sick, I took him to Chiquimula, and the doctor did an analysis, and said that with the prescription he would be cured. He gave me the prescription for the medicines. I left the hospital, I crossed the road, and I took the first truck that was heading up here, and I returned because I did not have the money to buy the medicines. That's how it is. If you don't have money, there is no way. And my son died two days later. ${ }^{8}$

Families spoke about malnutrition or hospitalisation in ways that suggest a struggle to keep control while confronting circumstances beyond their means. Women are told that they are responsible for their children's health, and survival, and this they do not contest, but they live without the conditions necessary to meet their children's basic needs.

Sprinkles are not a part of the solution to emergency scenarios; they are for stunting. The fear of acute malnutrition makes it very difficult for stunting to be placed in people's lives as a concern. An InterAmerican Development Bank (IDB) report criticises the Ministry of Health for a shift in focus to 'scour the country' to look for cases of acute malnutrition, calling it a distortion in priorities in reaction to 'occasional outbreaks' of acute malnutrition in the Dry Corridor (Martorell 2012: 37). In the communities I visited, malnutrition is understood and experienced very much in relation to this concern regarding acute malnutrition. Communication from health staff about why families should care about chronic malnutrition, what to do to about it, and even which children suffer from it, is inconsistent. On the one hand, while weight loss is easy to detect, stunting requires the plotting of numbers on a curve, and in some communities this information is not shared until a later monitoring date, if at all. Advice for families with stunted children often consists of reminders to wash hands and serve vegetables. Nurses told me that they rarely mention the importance of consuming animalorigin protein because they know families are unable to do so. One nurse in the district centre said that for the great majority 'it's too late' and that reducing stunting is 'very complicated'. Her colleague added that in fact it should be dealt with once girls are fertile, and asked out loud, frustrated,'But how can we reach all the adolescents, if we can't even reach all the mothers?', suggesting this was beyond the current capacity of the health system. During a visit to the regional health office, in response to my concern that chronic malnutrition did not always appear to be a priority for health staff, the nutritionist observed: 'Remember that chronic malnutrition does not kill' (in contrast to acute nutrition). Efforts to draw attention to stunting are also said to be hampered by widespread acceptance, even amongst some health practitioners, that Guatemalans are short by nature (Albizu 2015: 78; Chary et al. 2013).

\section{Birth Spacing and Malnutrition}

Sprinkles and advice on stunting were not at the forefront of women's concerns, and I found that many women made discreet reference to health advice they deemed much more crucial: birth spacing, or family planning. I chatted with Luzmilda, a pregnant mother resting on a bench outside a well-kept kitchen, her daughters playing beside her in clean flower-print dresses. Calm and resigned, she recounted:

I have had nine children, but three have died. And yesterday, the nurse said the little one has lost weight. It's because my milk is drying up with this pregnancy. She eats, but she needs milk too. They said to take her to Jocotán, but how am I going to go? I don't have any money.

Luzmilda's case introduces a discussion of the new way that health services and families are talking about malnutrition at the village level. As Luzmilda went on to tell me, she had hoped to avoid her current pregnancy: 'I went to get an injection, but the centre was closed, and just that next month I got pregnant again'. (The centre is an hour's walk up the hill, and staff are often absent due to activities scheduled elsewhere.) This topic is taboo for many people. One mother with seven children told me quietly, glancing to ensure that her father-in-law out on the patio was not listening: 'Now I am using family planning, but the pastor doesn't know that I am taking care of myself, even if God does know all. Some women do it without even their husband's knowledge'.

Although the health centre staff say that rates of use are low (one nurse offered an estimate of 40 us- 
ers out of 300 fertile women), family planning is a controversial topic at the community level. Some villagers described it as a sin, while for others the issue was not so straightforward. Several religious leaders said they were reflecting on which is the worse sin: birth control or death from malnutrition, or in one man's words: 'not to have children or to have them in hunger'. Health centre staff are currently helping families see the link between 'spacing' and child health, especially for families that have suffered the loss of a toddler due to a new baby being born soon thereafter. One young mother told me: 'I got the injection after my son died, from being thin, because of the new baby. I got it the same day'. Another mother said that she lost her newborn, who was very thin, and that her one-year-old son remained very small, as her breast milk was scarce: 'That is why I did family planning. My husband said, "Let's do it, we don't want our children to suffer"'. Women are learning of the risks of close pregnancies for the well-being of their children, who, in conditions of scarcity, are highly reliant on breast milk. (Children continue to consume breast milk as an important source of food up to one year of age and beyond.) Women do not buy infant formula for babies, due to its prohibitive cost. Although several young mothers told me how they had passed the nurse's information on to their husbands and had managed to start using contraceptives, others attempted to space 'naturally' (referring to methods such as watching their cycles), and that both methods have been mentioned to them as ways to avoid child health emergencies.

\section{Education: A New Vision}

Reactions to both sprinkles and birth spacing can best be understood by looking at strategies developed in the face of precarity, but they should also be considered in light of shifting expectations or visions for family life. An ideal family, for most people I met, is a large family. A large family brings 'happiness' because one has company, and, as one mother in her thirties, pregnant, and with seven children, expressed, it is an economic decision: 'Will I have more children? Only God knows. We want children to work. They go out and earn money'. Even if fertility (average number of children per woman) is declining in Guatemala, from 5.7 in 1985 to 3.7 in 2015 (UNICEF 2015), in the communities I visited large families are still common (the authorities report that village populations are rapidly increasing). Several women I met had nine or ten children, many had eight, and one of them was only 32 years old. However, for some, the logic of the large family is starting to shift. One younger mother explained that because her family was small the money her husband made was enough to feed them all and to ensure better meals for their children. Another farmer, whose youngest brother had managed to finish training as a nurse, made the following comment:

I would like my children to become more than I am, that they manage to be professionals. I will fight for it. As well, I am thinking about family planning ... I think with two children we are fine, maybe three. Any more, and it is difficult to educate them and it's hard to find enough food.

This is not the norm: most people, when queried, suggested that their children's lives would be similar to their own, surviving on seasonal agricultural labour while tending to their plot of land. As one father said, 'They will be here; they will be like me; they will look for a piece of land to plant'. However, this vision is under stress. A father of three admitted: 'I see that each person will eventually have less land, and I think about education. We have to make an effort to get education'. This, unfortunately, is almost impossible under current conditions, as education beyond the sixth year of primary school is a real luxury. 'How will we pay for school if we don't have food?', said one grandfather, referring to the cost of books, uniforms, travel and school fees. In one of the communities where this research was carried out, only six students are currently enrolled beyond primary school, which is over an hour's walk away (there are about 70 students in the primary school). ${ }^{9}$ In the other community, which is even more remote, only one student was taking secondary school courses, and did so through a distance programme over the radio.

None of those enrolled in secondary education are girls, and both mothers and teachers linked this to the fear of sexual violence. A village primary school teacher complained that 'adolescents come to the school to bother the girls, to look at them. We beg the girls to go to secondary school, but they fear the walk'. As soon as their bodies start to change, many girls leave the village school. I only found one family that insisted that their daughters would continue beyond primary education. An air of hopelessness pervades the topic of further education, not only because it is unaffordable and because there are fears surrounding safety, but because there is a lack of faith that further employment will later be found. Very few farming families have the resources, contacts 
or know-how to gain non-agricultural employment, and the isolation implied by this fact appears to be much more than the one-hour drive to the district capital. This is especially true for women. Both girls in elementary school and their mothers explain that the role of women is to be at home, 'making tortillas'. Many women I spoke to rarely leave the community, as men generally purchase food and even their wives' clothing. ${ }^{10}$

How is this relevant to the discussion on sprinkles? Investment in children has to do with the way that families envision their future within the limits of what they view as possible. In rural areas of the Peruvian Andes, I noted that mothers have begun to link intelligence and scholarly achievement with nutrition, which has shaped their response to public health messages (Gillespie 2017). Despite all the limitations described above, some of these ideas are starting to circulate in rural communities in Guatemala. One mother told me that sprinkles would 'refresh the mind', and another had heard they would improve school performance. Several worried that an episode of acute malnutrition had left an impact on a child's development. As Laura observed, 'My son has been in the first year of primary for three years; he doesn't pass. My husband said to let him leave school. ... I think his mind fails him; his mind fails him maybe because of lack of food'.

While there is still a disconnect between the use of sprinkles and any observable benefit for babies or families, family planning is trickling into conversations in some families, not only to ensure that babies thrive, but to ensure that the family itself thrives in the longer term. It will likely be those families that may, too, be able to make further use of nutrition information that comes their way.

\section{Medicalisation and Women's Decision-Making}

This research joins existing work on the challenges faced in making use of sprinkles. Evidence of the product's potential impact is well-documented (Jack et al. 2012; UNICEF 2013; Zlotkin et al. 2005), and they are increasingly adopted as part of nutrition programmes. They are now used in 50 countries (Tumilowicz et al. 2017), and UNICEF (2013) recorded a ten-fold increase in demand from 2007 to 2012. However, a range of unforeseen difficulties have come to light. While some trials did indicate initial acceptance on the part of caregivers, for example, in Bangladesh (Karim et al. 2006), in other contexts, such as Peru, caregivers were reticent to continue use (CreedKanshiro et al. 2016; Huamán-Espino et al. 2012). A study in a refugee camp in Kenya captured mothers' concerns that they did not have enough food to meet their children's ensuing increased appetites (Kodish et al. 2011: 299). Sprinkles in theory may work well on the body, but recent scholarship has found that, although the 'apparent simplicity' of the product was thought to be a central feature of its attractiveness, in fact the successful use of sprinkles depends on a 'complementary feeding process that requires a complex set of caregiver behaviours and caregiverchild interactions' (Tumilowicz et al. 2017: 8). Emily Yates-Doerr's work in Guatemala offers important critiques of what she labels 'nutritional blackboxing', which is 'the process of consolidating technical and historically contingent ideas about nourishment and the myriad relationships surrounding dietary practices into seemingly unproblematic terms: a vitamin, a nutrient' (2012: 294) and the mismatch between universal nutrition education messages and the messy reality of everyday life. As she recounts, a mother in a Guatemalan city commented that, even if considered nutritious, fruit sold on the street, cut with a possibly dirty knife or washed with contaminated water, may not be a healthier snack than a bag of chips for her little children if she was not there to prepare the fruit herself (Yates-Doerr 2012). While in Chiquimula, I found that mothers doubted that an egg with sprinkles, left uneaten, had more food value than an egg without them that was consumed by a toddler.

Margaret Lock and Vinh-Kim Nguyen place these types of interventions in historical context by tracing the 'discovery of malnutrition' (2010: 163). They describe how colonial observation linking certain diseases with dietary scarcity, and later on work in refugee camps to standardise measurement techniques, opened the door for the new area of nutrition science, within which trials were developed to evaluate the impact of nutritional interventions on bodies (165). In this process, hunger and nutrition came to be redefined as clinical problems; populations could be rescued with the administration of nutrients, conceptually removing these issues from their roots in political or social disruption (168). Biomedical treatments may shift issues such as food scarcity to the sidelines, as in the case of the large-scale administration of vitamin A supplements that Ian Harper documents in Nepal (Harper 2014).

Scholarship on nutrition policy also recognises that administering nutrients to the body does not function in isolation, as can be seen in the movement from 
'nutrition-specific' to 'nutrition-sensitive' programming, which calls for investment in agriculture, social safety nets, early childhood development, and education to enhance nutrition interventions (Ruel and Alderman 2013). Marie Ruel and Harold Alderman (2013) have argued that women's empowerment and income-generation and other such underlying determinants of malnutrition should be addressed. Policy actors and international aid experts in Guatemala now insist that, unless structural issues such as poverty and inequality (along urban-rural, ethnic and gender lines) and deficiencies in education and job creation are addressed, it will be very difficult to significantly reduce malnutrition (ASIES 2017). This approach is evident on paper (Comisión 2016), but it does not trickle down to operative actions on the ground. In fact, the authorities that I interviewed in the region of study focused heavily on behaviour change education as the solution to high rates of stunting in local communities. Health professionals' awareness of the fact that a lack of land, income, food and clean water complicate any adherence to behaviour change recommendations and undermine national strategies for reducing stunting was not shared by all government representatives. According to one district-level authority, referring to local villagers, 'they have food, and work, even if they don't own the land ... but there they are dirty and messy'. Comments such as these point to families' habits as the source of the problem. Several policy actors in Guatemala mentioned that this attitude represents an intent to distance poverty from malnutrition, and studies are now being circulated that show instances where malnutrition has been reduced while poverty remains virtually unchanged, as working on behaviour change is easier than addressing the issue of salaries, for example. ${ }^{11}$ The emphasis on enhancing nutrition education and the focus on the family as the point of responsibility for solving the problem partially enables officials to sidestep the issues of inequality, poverty and the inadequate functioning of the state.

An emphasis on education for behaviour change runs the risk of reproducing discriminatory social relations when families, due to a lack of capacity or resources, fail to react, opening the door to new externally imposed moral standards. Existing ways of coping collide with the expectations of health and development actors (Mariano Juarez 2014), as we saw from the nurse's frustration when very ill babies were not rushed to the hospital. This scenario echoes Nancy Scheper-Hughes's (1992) observations regarding the reality that the weakest children die in cases of extreme poverty and malnutrition in Brazil and how social norms grow to cope with it. When food scarcity is medicalised as malnutrition, the responsibilities of medical staff and their moral codes may collide with a local reality that is beyond what public health can solve. This, too, is reminiscent of ScheperHughes's account, in which she asks a health nurse why more is not done for malnourished children at the clinic, who in turn observes that there is not much she can do, saying: 'We can't prescribe food!' (1992: 154).

Malnutrition is a marker on the body of general lack of well-being and the impact of disadvantage. Public health monitoring and detecting of malnutrition are after-the-fact actions, and only really make sense as part of a larger multi-sector approach. ${ }^{12}$ Sprinkles may very well prove to be helpful, but these kinds of initiatives can only work in conjunction with changes to material conditions; otherwise, they lose their legitimacy for the families involved.

In the context that I have described above, where mothers are focused on seeing their families through periods of food scarcity and the ongoing concern of child illness, they will, in their capacity, make use of any services that do come their way. As one elderly villager told me, 'We are poor here; we will take what we can get'. Margaret Lock and Patricia Kaufert's work on pragmatism in women's health decisions is a useful point of reflection. As they explain, women's relationships with medical technology are 'usually grounded in existing habits of pragmatism ... if the apparent benefits outweigh the costs to themselves, and if technology serves their own ends, then most women will avail themselves of what is offered' (Lock and Kaufert 1998: 2). Spacing has started to make sense, and sprinkles may too become worthwhile, for the less vulnerable families, who have started to see them as useful in the context of new visions for their children. As I said above, women must be able to use the product and they must be motivated to do so as well.

Discussion around motivation is central to understanding women's reactions to public health advice. Naila Kabeer (1999) understands agency as the capacity to define one's goals and to act on them, and it includes the motivation, purpose and meaning that individuals bring to their actions. Keya Maitra (2013) describes a feminist agency that includes women's ability not simply to make choices, but to formulate them, implying an awareness, or a consciousness, of not just how things are, but of how they could be. I suggest that women's precarious conditions not only make sprinkles materially unsuitable, but also 
work to shape families' expectations for the future. Women's expression of agency in health decisionmaking is limited at various levels: while targeted as recipients of messages promoting individual behaviour change as a solution to child malnutrition, they lack the material conditions and often the autonomy to carry out these behaviour changes. And at the same time, their goals, too, correspond to the stifling limitations imposed by the enduring structures of inequality with regard to access to services, resources and opportunities. As well as being difficult, the 'meaning, motivation and purpose' (Kabeer 1999: 438) surrounding sprinkles are intangible: they correspond to a problem or a vision still beyond what is voiced locally as a priority. Spacing, however, has begun to enter the nutrition discourse as a way for women in Guatemala to take some control of their situation, to more than just survive. It is being seen as a useful tool that be used within their specific, marginal socio-economic situation.

\section{Conclusion}

This article echoes scholarship calling for more indepth research on how nutrition outreach work fits within existing realities, and it adds further evidence for the position that without attention to the outstanding issues of poverty and living conditions nutrition-specific work is of limited use. Parents find themselves in an untenable position - they are fully responsible yet unable to fully respond. Despite families' efforts to manage child illness and malnutrition in a context of poverty, they face constant challenges due to vulnerable living conditions, a lack of sanitation, and insufficient means to feed their family, let alone to earn a living. The distribution of an expensive product, sprinkles, within underfunded health systems only to go to waste raises serious questions about its inclusion as a central element. Furthermore, this research raises ethical questions about the distribution of sprinkles (which require food to be consumed) when the government's response to predictable food shortages exists largely on paper. Farming communities without land face an inviable future, and farmers are targeted with supplements for children's physical and cognitive growth. And yet access to education for these children, education which will help them gain new forms of employment, is all but impossible.

I have suggested that families' situations shape their reactions to new health information, not only in terms of their material capacity to respond, but also in terms of their expectations, or the meaning they can find for new health information within their lives. The research setting (Guatemala's Dry Corridor) has offered a very interesting example of how some healthcare personnel have noted the real challenges and fears facing community members, and how in response to these fears and challenges families have begun to contest existing norms to make new health-related decisions (family planning) to avoid a downward cycle of illness, malnutrition and accompanying costs and crisis. Interest in medical options for birth spacing has grown, partly to avoid emergency, but it has entered some families' talk of a new vision for their futures. Sprinkles too may be found to have a logic in that sense, but this will require not only an increased visibility of the threat of chronic malnutrition, but an increased visibility of the people themselves as having a claim to resources and opportunities within the state.

Bronwen Gillespie has a PhD in Anthropology from the University of Sussex, and specialises in global health and development. Her ethnographic work explores women's agency in reaction to public services in the Peruvian Andes and examines concepts of reproductive governance and social inclusion. She currently works as an independent researcher and development consultant, and has done so most recently in Guatemala and Cuba.

Email: gillespiebronwen@yahoo.es

\section{Notes}

1. All names have been changed to respect the informants' anonymity.

2. I am grateful to ACF for funding this research project. The data is my own, and the views expressed here are not necessarily shared by ACF or its partners. In Guatemala, ACF works hand-in-hand with health, agriculture and economic development ministries, the food security commission, and local authorities.

3. The Guatemalan currency is the quetzal $(\mathrm{Q})$.

4. World Food Programme (WFP) donations.

5. During this fieldwork, several medical professionals mentioned that national health policy had very recently changed to allow pills to be prescribed for children at one year of age.

6. A commercial corn and soy based cooked cereal that contains added vitamins and minerals.

7. This can be balanced, however, by views of families we met at the nutrition centres, who are intent on 
having children interned in order to recuperate. Once a child has severe acute nutrition, they cannot be easily treated at home, according to the prevalent medical opinion.

8. At least 9 of the 65 families I visited had lost a child.

9. This is an achievement, as many of the fathers and almost all the mothers are illiterate.

10. They do leave for health emergencies and, recently, to attend meetings held by international organisations, required to receive food aid.

11. Author interviews with the Food and Agriculture Organization (FAO) of the United Nations, the Asociación de Investigación y Estudios Sociales (ASIES) [Association of research and social studies], and the Secretaría de Seguridad Alimentaria y Nutricional (SESAN) [Food and nutrition security secretariat] in Guatemala.

12. I am grateful to Jody Harris and other Institute of Development Studies (IDS) and University of Sussex colleagues for contributing to discussions on these issues.

\section{References}

ACF (2016), Systems Enhancement for Transformative Health. Project Implementation Plan (Guatemala City: Action Against Hunger).

ACF (2017), Systems Enhancement for Transformative Health. Baseline Report (Guatemala City: Action Against Hunger).

Albizu, J. L. (2015), ‘La violencia médica o la violencia por tu propio bien', in M. Camus, S. Bastos and J. López (eds.), Dinosaurio Reloaded: Violencias Actuales en Guatemala (Guatemala City: FLACSO, Fundación Constelación), 63-84.

ASIES (2014), Análisis de la situación de Seguridad Alimentaria y Nutricional en Guatemala e implementación pública del Plan SAN (Guatemala City: Asociación de Investigación y Estudios Sociales).

ASIES (2017), Revisión Estratégica de la Situación de Seguridad Alimentaria y Nutricional en Guatemala con Énfasis en la Desnutrición Crónica y sus Determinantes (Guatemala City: Asociación de Investigación y Estudios Sociales).

Berry, N. (2008), 'Who's Judging the Quality of Care? Indigenous Maya and the Problem of "Not Being Attended"', Medical Anthropology 27, no. 2: 164-189. doi:10.1080/01459740802017413.

Chary, A., S. Messmer, E. Sorenson, E. Henretty, S. Dasgupta and P. Rohloff (2013), 'The Normalization of Childhood Disease: An Ethnographic Study of Child Malnutrition in Rural Guatemala', Human Organization 72, no. 2: 87-97.
Comisión (2016), Estrategia Nacional para la Prevención de la Desnutrición Crónica 2016-2020 (Guatemala City: Comisión Nacional para la Reducción de la Desnutrición Crónica). http://www.sesan.gob.gt/ wordpress/wp-content/uploads/2017/07/Estrategiapara-la-Prevencion-de-la-Desnutricion-Cronica.pdf. Accessed on 8 May 2015.

Conrad, P. (1992), 'Medicalization and Social Control', Annual Review of Sociology 18, 209-232.

Creed-Kanashiro H., R. Bartolini, M. Abad and V. Arevalo (2016), 'Promoting Multi-micronutrient Powders (MNP) in Peru: Acceptance by Caregivers and Role of Health Personnel', Maternal and Child Nutrition 12, no. 1: 152-163.

Foucault, M. (1973), The Birth of the Clinic (New York: Pantheon Books).

Gillespie, B. (2017) 'Negotiating Nutrition: Sprinkles and the State in the Peruvian Andes', Women's Studies International Forum 60C: 120-127. doi:10.1016/ j.wsif.2016.10.009.

Harper, I. (2014), Development and Public Health in the Himalayas: Reflections on Healing in Contemporary Nepal (London: Routledge).

Huamán-Espino, L., J. P. Aparco, E. Nuñez-Roble, E. Gonzáles, J. Pillaca and P. Mayta-Tristán (2012), 'Consumption of Chispitas ${ }^{\circledR}$, Multimicronutrient Supplements and Anemia in 6-35-Month-Old Children: Cross-Cut Study in the Context of a Populational Health Intervention in Apurimac, Peru', Revista Peruana de Medicina Experimental y Salud Pública 29, no. 3: 314-323. (Spanish).

Jack, S., K. Ou, M. Chea, L. Chin, R. Devenish, M. Dunbar, C. Eang, K. Hou, S. Ly, M. Khin, S. Prak, R. Reach, A. Talukder, L. O. Tokmoh, S. Leon de la Barra, P. C. Hill, P. Herbison and R. S. Gibson (2012), 'Effect of Micronutrient Sprinkles on Reducing Anemia: A Cluster-Randomized Effectiveness Trial', Archives of Pediatrics and Adolescent Medicine 166, no. 9: 842-850. doi:10.1001/ archpediatrics.2012.1003.

Kabeer, N. (1999), 'Resources, Agency, Achievements: Reflections on the Measurement of Women's Empowerment', Development and Change 30: 435-464.

Karim, F., N. Choudhury, A. Pasha, K. Hasan, S. M. Ziauddin Hyder and S.H. Zlotkin (2006), Reaching Sprinkles to Millions: Social Marketing Strategy for Combating Childhood Iron Deficiency Anemia (Dhaka: Brac Centre).

Kodish, S., J. Hyun Rah, K. Klaus Kraemer, S. de Pee and J. Gittelsohn (2011), 'Understanding Low Usage of Micronutrient Powder in the Kakuma Refugee Camp, Kenya: Findings from a Qualitative Study', Food and Nutrition Bulletin 32, no. 3: 292-303. 
Lock, M. and A. Kaufert (1998), Pragmatic Women and Body Politics (Cambridge: Cambridge University Press).

Lock, M. and V. K. Nguyen (2010), An Anthropology of Biomedicine (Chichester, UK: Wiley Blackwell).

Maitra, K. (2013), 'The Questions of Identity and Agency in Feminism without Borders: A Mindful Response', Hypatia 28, no. 2: 360-376.

Mariano Juarez, L. (2014), Las Hambres en la región Ch'orti' del Oriente de Guatemala: Cultura, Política y Representación en los Diálogos de la Cooperación y el Desarrollo (Pamplona: G9 Editorial).

Martorell, R. (2012), Interventions and Policy Options for Combating Malnutrition in Guatemala (New York: Inter-American Development Bank, Country Department Belize, Central America, Mexico, Panama and Dominican Republic, Social Protection and Health Division).

MFEWS, FAO and SESAN (2009) Guatemala: Perfil de Medios de Vida Zona 8: Granos básicos, zona fronteriza con Honduras y El Salvador (Guatemala City: Sistema Mesoamericano de Alerta Temprana para Seguridad Alimentari, Food and Agriculture Organization and Secretaría de Seguridad Alimentaria y Nutricional).

MSPAS (2013), Guía para la Suplementación Preventiva con Vitaminas y Minerales Espolvoreados (Guatemala City: Ministerio de Salud Pública y Asistencia Social).

MSPAS, INE and SPP (2017), Encuesta Nacional de Salud Materno Infantil 2014-2015. Informe Final. (Guatemala City: Ministerio de Salud Pública y Asistencia Social, Instituto Nacional Estadística and Secretaría de Planificación y Programación de la Presidencia).

Presser, H. and G. Sen (2000), Women's Empowerment and Demographic Processes: Moving Beyond Cairo (New York: Oxford University Press).
Ruel, M. T. and H. Alderman (2013), 'NutritionSensitive Interventions and Programmes: How Can They Help to Accelerate Progress in Improving Maternal and Child Nutrition?' The Lancet 382, no. 9891: 536-551. doi:10.1016/S0140-6736(13)60843-0.

Scheper-Hughes, N. (1992), Death without Weeping: The Violence of Everyday Life in Brazil (Berkeley: University of California Press).

SESAN (2017), Pobreza de Chiquimula y su situación de desnutrición (Chiquimula: Secretaría de Seguridad Alimentaria y Nutricional).

Tumilowicz, A., C. Held Schnefke, L. M. Neufeld and G. H. Pelto (2017), 'Toward a Better Understanding of Adherence to Micronutrient Powders: Generating Theories to Guide Program Design and Evaluation Based on a Review of Published Results', Current Developments in Nutrition 1, no. 6: e001123. doi:10.3945/cdn.117.001123.

UNICEF (2013), Multiple Micronutrient Powder Supply and Outlook (Guatemala City: United Nations International Children's Emergency Fund).

UNICEF (2015), More Investment: We've Advanced, but Children and Adolescents Need More Social Investment (Guatemala City: United Nations International Children's Emergency Fund).

Yates-Doerr, E. (2012), 'The Opacity of Reduction', Food, Culture and Society 15, no. 2: 293-313. doi:10 .2752/175174412X13233545145381.

Zlotkin, S. H., C. Schauer, A. Christofides, W. Sharieff, M. C. Tondeur and S. M. Z. Hyder (2005), 'Micronutrient Sprinkles to Control Childhood Anaemia', PLoS Medicine 2, no. 1: e1. doi:10.1371/journal.pmed .0020001 . 